\title{
Study on Technological Innovation Risk of China's e-Services
}

\author{
Xiaobin Lu \\ School of Information Resource Management, Renmin University of China, \\ Beijing 100872
}

\begin{abstract}
Technological innovation risks of China's e-Services include such factors as policy, economy, technology, market and resources. Based on analyzing the above factors, the Article has designed the assessment system for technological innovation risk of China's e-Services, discussed on the assessment method of analytical matrix and proposed the particular measures for preventing China's e-Services technological innovation risk.
\end{abstract}

Technological innovation of e-Services is the core power for e-Business. The development and the success in technological innovation of e-Services will bring huge interests for e-Business, but due to the systematic and complicated features of technological innovation for e-Services, it is also a high-risk activity [1].

The research group of the program for the National Natural Science Foundation of China (70573119), "Demonstrative Study on Technological Innovation of China's Information Service" and New Century Excellent Talents in University (NCET-040049), "Theoretical Study and Case Analysis on Technological Innovation of China's e-Services" had investigated 30 e-Business websites in China (e.g.,Alibaba.com, ebay.com, ChinaCCM.com, Made-in-China.com, joyo.com, etc.) during 2005-2006. The content of questionnaire comprises 4 respects (Table 1).

Table 1. . Content of Questionnaire

\begin{tabular}{|l|c|c|c|}
\hline $\begin{array}{c}\text { Types of } \\
\text { investigation }\end{array}$ & $\begin{array}{c}\text { Objects } \\
\text { of investigation }\end{array}$ & $\begin{array}{c}\text { Amount of } \\
\text { questionnaire }\end{array}$ & $\begin{array}{c}\text { Explanation of } \\
\text { questionnaire }\end{array}$ \\
\hline $\begin{array}{l}\text { Technological } \\
\text { innovation } \\
\text { risks }\end{array}$ & $\begin{array}{c}30 \text { e-Business } \\
\text { websites in China }\end{array}$ & $\begin{array}{c}28 \text { (available), } \\
2 \text { (no available) }\end{array}$ & $\begin{array}{l}\text { Main person in charge } \\
\text { of e-Business websites }\end{array}$ \\
\hline
\end{tabular}

The conclusions have been obtained on the basis of analysis of the content of questionnaire: $65 \%$ of e-Services technological innovation projects have made technological achievements, but only $9 \%$ of e-Services technological innovation projects have been marketed. Because of the high risk and the risk's uncertainty,

Please use the following format when citing this chapter:

I., X., 2007, in IFIP International Federation for Information Processing, Volume 252, Integration and Innovation Orient to E-Socicty Volume 2. eds. Wang, W., (Boston: Springer), pp. 252-261. 
complicity and objectiveness, when the enterprises undertaking e-Business carry out technological innovation of e-Services, failure has always been in companion. Consequently, many of the enterprises, especially small and medium enterprises fear excessively the risk that they shrink back at the sight of e-Services technological innovation and dare not to undertake e-Services technological innovation and thus lose the fine opportunity for development.

The excessively high risk of e-Services technological innovation will not naturally determine the fate of the results of e-Services technological innovation, while they will depend on the effective management over the innovation process [2]. If we carry out the total analysis and investigation over all the segmental risk factors affecting the success and failure of e-Services technological innovation, have a full understanding of innovation risks and formulate better prevention measures for these possible risks, technological innovation risks of e-Services will be minimized.

\section{Factor Analysis on Technological Innovations Risks of China's e-Services}

\subsection{Policy risk factor}

China's economic development target in different periods and changes of social demand will all influence the orientation of e-Services technological innovation. Changes in the government's overall economic development planning, regional development planning and development planning for information industry and eBusiness will all cause risks to China's e-Services technological innovation. Projects in compliance with the government's development target, development planning and policy for information industry and e-business will be supported and sponsored by the government and enterprises; otherwise, they may be restructured by the government for development and may encounter the policy risk. The change of the government's macro development target influences the change of social demand. It will be easy for those projects of e-Services technological innovation in compliance with the development demand of e-business to obtain social support and reduce the risks in commercialization of innovation [3].

\subsection{Economic risk factor}

Development of China's economic circumstance has a major influence over the success or failure of e-Services technological innovation, as is mainly reflected in the people's online shopping capacity and market demand. With the economy flourishing, the people's online shopping capacity is strong and market demand is vigorous, as will promote the activities for e-Services technological innovation and reduce the risk in marketing the technological innovation of e-Services; otherwise, it 
will not be beneficial to undertake the activities for technological innovation of eServices and increase the marketing risk. The development of China's economic circumstance will directly influence the financing for the technological innovation of e-Services.

\subsection{Technical risk factor}

Technical factor is the objective reason for technological innovation risk of eServices for the uncertainty of technological research and difficulty of innovation technology will directly determine the technological innovation risk of e-Services. As for some copy and transform innovation projects with breakthrough in key technology and mature supporting technologies, the technical risk of innovation will be reduced to a great extent, while for those projects of the essential innovation with comparatively high technical standard that will bring enterprises high returns once a breakthrough is made in the key technology, the innovation risk will be comparatively high.

\subsection{Market risk factor}

Technological innovation of e-Services is a process of integrating the market opportunity with the technical opportunity. The marketing and commercial benefit is the final standard for testing if the innovation is successful or not. Therefore, market factor is the key factor influencing technological innovation risk of e-Services in China, including mainly: (1) improvement of market regulations: with incomplete regulations, different types of tort will appear and innovators will not be able to enjoy the expected innovation returns. (2) Status of market demand: the consumers' preferential and its duration, scale of market demand and opportunity for a high tide of market demand will all influence the marketing of innovation products [4].

\section{Design of Assessment System for Technological Innovation Risks of China's e-Services}

According to the above analyses on the risk factors, we will design the comprehensive indicators system for technological innovation risks of China's eServices in the five respects of environmental factor, market factor, technical factor, financial factor and management factor.

\subsection{Environmental factor}

a. Policy and law environment: the indicator is used to display the uncertainty of policy and law environment. China's policy and law environment has to a great 
extent determined the speed, direction and scale and even success or failure of technological innovation for e-Services. b. Macro economic situation: it is an indicator used to describe the influence of China's overall economic status on the technological innovation for e-Services. Generally, with the economy flourishing, the technological innovation risk is low, while with the economy depressing, the risk is high.

\subsection{Market factor}

c. Market acceptance capacity. Technological innovation products of e-Services are brand-new products. With the products introduced, it is not so easy for consumers to timely understand about their performance that they will keep an attitude of wait and see or make a wrong assess. Therefore, it is difficult to estimate accurately if the market can accept and how big the market capacity is. d. Extent of not being influenced by the competitors. In all the stages of executing technological innovation projects of China's e-Services, there will be always competitors or potential competitors and thus it is definite that they will be influenced by the competitors, while the extent of influence depends on the number, strength and competing measures of competitors. e. Promotion capacity. Objectively speaking, if market potential is excessively strong or the barrier for marketing is comparatively sold, it will cause difficulties for promoting the technological innovation products of China's e-Services. Subjectively speaking, the indefinite market orientation for technological innovation products of e-Services is the main reason for unfavorable market promotion.

\subsection{Technical factor}

f. Technical force. This comprehensive indicator is reflected in: firstly, e-Business companies' strength of scientific research force and technical accumulation; secondly, technical equipment, process and experimental conditions of enterprises undertaking e-Business. g. Technical leadership: i.e., the extent of the technology of the innovation activity leads the current average standard. h. Technical difficulty. In the stage of production, the more difficult the technology, the higher technical risk and production risk will be brought to the enterprises undertaking e-Business. With the new products marketed, the higher the technical difficulty, the stronger the access barrier is for the competitors and the market risk is low. i. Technical prospect. At birth, the technological innovation products of China's e-Services are normally incomplete and even rough. The innovators are not sure if they can soon improve the products under the current technical conditions. Additionally, it is uncertain if the new products can bring the anticipated effect and will be eliminated or restricted for selling due to the technical defects. The uncertain factor of all these technical prospects will possibly cause a risk for the technological innovation of China's eServices. 


\subsection{Financial factor}

j. Financial strength of enterprises undertaking e-Business. The financial strength of enterprises undertaking e-Business is an important aspect reflecting their projection capacity for innovation and capacity of bearing risks. k. Financing capacity of enterprises undertaking e-Business. In carrying out the technological innovation activities of e-Services, enterprises undertaking e-Business not only need to have strong financial capacity, but also strong financing capacity to handle all different possible emergencies and other emergent financial demands. 1. Status of financial operation. The financial operation status of the enterprise undertaking e-Business enterprises can show risk potential of the project.

\subsection{Management factor}

$m$. Comprehensive qualification of the project in-charge. Here, the project in-charge is extensively defined: it can mean an in-charge of a project as well as the steering group of the project. The comprehensive qualification of the project in-charge covers his work experiences, knowledge standard, organization and management capacity, occupational morality and sense of innovation and risk. n. Performance of organizational structure: i.e., the effect and function on the technological innovation project of e-Service by the setup and operation of the organizational structure [5].

\section{Assessment Method of Analytical Matrix for Technological Innovation Risk of China's e-Services}

\subsection{Analytical matrix}

Analytical matrix is shown in Table 2, whereas Aij indicates a stage in the e-Services technological innovation, having a risk factor with a certain feature.

Table 2. Analytical Matrix for Technological Innovation Risk of e-Services

\begin{tabular}{|l|c|c|c|c|c|c|}
\hline $\begin{array}{c}\text { Stages of } \\
\text { innovation }\end{array}$ & $\begin{array}{c}\text { Technica } \\
\text { I risk }\end{array}$ & $\begin{array}{l}\text { Market } \\
\text { risk }\end{array}$ & $\begin{array}{c}\text { Financing } \\
\text { risk }\end{array}$ & $\begin{array}{c}\text { Production } \\
\text { risk }\end{array}$ & $\begin{array}{c}\text { Manageme } \\
\text { nt risk }\end{array}$ & $\begin{array}{c}\text { Policy } \\
\text { risk }\end{array}$ \\
\hline $\begin{array}{l}\text { Innovation } \\
\text { assumption }\end{array}$ & $\mathrm{A}_{11}$ & $\mathrm{~A}_{12}$ & $\mathrm{~A}_{13}$ & $\mathrm{~A}_{14}$ & $\mathrm{~A}_{15}$ & $\mathrm{~A}_{16}$ \\
\hline $\begin{array}{l}\text { Survey and } \\
\text { evaluation }\end{array}$ & $\mathrm{A}_{21}$ & $\mathrm{~A}_{22}$ & $\mathrm{~A}_{23}$ & $\mathrm{~A}_{24}$ & $\mathrm{~A}_{25}$ & $\mathrm{~A}_{26}$ \\
\hline $\mathrm{R} \& \mathrm{D}$ & $\mathrm{A}_{31}$ & $\mathrm{~A}_{32}$ & $\mathrm{~A}_{33}$ & $\mathrm{~A}_{34}$ & $\mathrm{~A}_{35}$ & $\mathrm{~A}_{36}$ \\
\hline $\begin{array}{l}\text { Pilot } \\
\text { experiment }\end{array}$ & $\mathrm{A}_{41}$ & $\mathrm{~A}_{42}$ & $\mathrm{~A}_{43}$ & $\mathrm{~A}_{44}$ & $\mathrm{~A}_{45}$ & $\mathrm{~A}_{46}$ \\
\hline
\end{tabular}




\begin{tabular}{|l|l|l|l|l|l|l|}
\hline $\begin{array}{l}\text { Batch } \\
\text { production }\end{array}$ & $\mathrm{A}_{51}$ & $\mathrm{~A}_{52}$ & $\mathrm{~A}_{53}$ & $\mathrm{~A}_{54}$ & $\mathrm{~A}_{55}$ & $\mathrm{~A}_{56}$ \\
\hline Market sales & $\mathrm{A}_{61}$ & $\mathrm{~A}_{62}$ & $\mathrm{~A}_{63}$ & $\mathrm{~A}_{64}$ & $\mathrm{~A}_{65}$ & $\mathrm{~A}_{66}$ \\
\hline
\end{tabular}

\subsection{Risk dimension of analytical matrix}

(1) Technical risk: means the possibility of innovation failure due to the uncertainty of technical factor and its change in the technological innovation of e-Services.

(2) Market risk: means the possibility for technological innovation failure of eBusiness due to uncertainty of relevant market factor and its change.

(3) Financing risk: means the possibility for innovation failure due to uncertainty of factor and its change influencing the fund raising, use and repayment for the technological innovation of e-Services.

(4) Production risk: means the possibility for innovation failure due to uncertainty of factor and its change in the production system in the technological innovation process of e-Services.

(5) Management risk: means the possibility for innovation failure due to the management error in the technological innovation process of e-Services.

(6) Policy risk: means the possibility for innovation failure due to the unfavorable influence of the central or local government's law, regulations, principle and policy and their change on the technological innovation project of e-Services.

For a technological innovation project of e-Services, according to the analytical matrix of risks, we can analyze systematically the possible risks and study the probability of occurrence and the possible loss extent so as to decide on the risks and carry out the effective risk management accordingly. Therefore, analytical matrix for technological innovation risk of e-Services has the following significances: (1) it is beneficial to make clear risk factors for technological innovation of e-Services and their co-relation; (2) since in practice the technological innovation activities of eServices are carried out at levels and in stages, innovation risk matrix can cooperate better in the risk management; (3) innovation risk matrix can provide risk analysis, estimation, control and investigation before, during and after the technological innovation activities of e-Services technological innovation, from which to find the rules so as to benefit the enterprises undertaking e-Business avoid the risks in innovation activities.

\section{Preventive Measures for Technological Innovation Risks of China's e-Services}

\subsection{Strengthen the governmental support and guidance to technological innovation of China's e-Services}

(1) Establish the information supporting system 
In the current commercial environment with rapid changes, for e-Business, it is critical to grasp such latest information as the governmental research achievements with potential and the production and operation of competitors. In China, many of the enterprises undertaking e-Business have inadequate sense of innovation for their technical progress, development of production technology development production and management skills for operation. Especially, it is extremely difficult for some small and medium enterprises to obtain high-quality and accurate information due to their isolated operation and lack of opportunities to exchange and learn with their colleagues. Therefore, it is necessary to strengthen the government's technical information service. For instance, through FEDWORLD network server, American National Technical Information Service provides customers with dial-network or INTERNET network information service and through the "chain" e-Supermarket provides the public with the wider and timely governmental information resources. These experiences are worth of reference [6].

(2) Regulate the intermediate service system for transform of innovation achievements

In order to raise the overall benefit of technological innovation for China's eServices, it is necessary to further cultivate and regulate the technical exchange market, energetically develop the productivity promotion center, business service center, technical broker and technical consulting companies and other intermediary organizations so that they can play an important role in the fields of achievement promotion, information provision and personnel training and build a bridge for the technological and economic integration. Additionally, it is also necessary to improve the auxiliary legal service organizations such as the technical contract arbitration committee, intellectual property firms, court for intellectual properties and promote the effective operation of technical market.

(3) Formulate effective technological policy

To cultivate the national technological innovation system for e-Services, it is not only to give a play to the market mechanism, but also more importantly to have the powerful policy guidance. America adopts a highly-developed free market economy system, but also the powerful governmental interference. Therefore, to formulate the national e-Business policy, China should also be deeply aware of the international competition environment China is faceting and the problems encountered in China's e-Business development, stress truly the features and comparative advantages of China, improve the relevant auxiliary policy and regulations and gradually generate the policy system with the technical progress of e-Services as the subject.

(4) Establish and regulate the venture investment mechanism

Development of venture investment industry is beneficial to guide the social idling capital fro investment in the technological innovation of e-Services, accelerate the industrialization of the achievements in technological innovation and reduce the loss due to the settlement and idling of scientific research achievements. For China's venture investment industry to really improve and develop and play a leading role in the technological innovation of e-Services, it is necessary to speed up the establishment of market economy system, i.e., to develop and improve the securities market, property exchange market, technology exchange market, establish the "secondary stock market" and accelerate the establishment of modern corporate 
system so as to create a fine market environment for the venture investment enterprises.

\subsection{Improve the risk management for the technological innovation of China's e-Services}

(1) Intensify the market survey and market forecast before the technological innovation of e-Services

Firstly, it is necessary to analyze the external operation environment, stress on understanding the law and regulations, trade policy, industrial policy, technical policy, and culture, nationality, religion and public psychology related to the technological innovation of e-Services so as to ensure the innovation products will not be constrained by the national law, regulations and policy and comply better with the requirement of social environment. Secondly, the success in technological innovation of e-Services does not necessarily mean an economic success. Time is the opportunity cost for a new and high technology to be transformed into innovative products with economic advantages, while the excessively early or late marketing of innovative products will both lead to a failure. Enterprises undertaking e-Business should carry out deliberate market study, timely discover new market and identify the declining of the current market and undertake the technical forecast and economic forecast.

(2) Stress on self competitive advantage and cautiously select the direction for the technological innovation of e-Services

For enterprises undertaking e-Business, if the elimination ratio is not so high in the initial stage of technological innovation for e-Services, it is possible move some development projects with impossible technical success or market success to the later stage of innovation, as will settle and collect the risks and eventually lead to increase or further expansion of risks and even cause the operation crisis of enterprises. Therefore, the enterprises undertaking e-Business must undertake corresponding countermeasures and formulate, in combination with their features and market status, different feasible optional solutions and carry out multi-stage assessment, set the control point of risks in the initial stage of innovation as far as possible and relief the possible risks as early as possible.

(3) Implement the progress control and risk monitoring for technological innovation of e-Services

It is necessary to establish the effective regulation and control mechanism, while the management should change along with the change of innovation activities. It is to raise the flexibility of organization as well as to strengthen the rigidity of organization, for an integration of the flexible and variable, planned and intentional supervision, control and management. It is necessary to constantly raise the technical qualification of engineering technical personnel and production workers and enhance the market sense of marketing personnel. Since there may be risks of different features in the entire process of technological innovation for e-Services technological innovation, such as technical risk, market risk, management, decision and other risks, in considering the assessment for the innovation project, it is not only necessary to carry out the pre-event study, but also the interim and post-event studies and to 
assess all the stages: i.e., the one single assessment is changed for a multi-stage assessment and the single decision making to the multi-stage decision making.

\subsection{Stress on the application of prevention technology for technological innovation risk of China's e-Services}

(1) Risk transfer

Risk transfer for technological innovation of e-Services means that part or all of the innovation risks are transferred from one undertaking entity to another undertaking entity, in two modes: (1) financial transfer: the undertaking entities of innovation activities remains, but the undertaking entities of risk loss have increased. Through participating in the project insurance and absorbing external investment, the enterprises undertaking e-Business carry out such transfer. (2) Objective transfer: it is to transfer part or all of the innovation activities from one undertaking entity to another undertaking entity, in such modes as technical transfer, consigned development, joint technological innovation, etc. Since the risk transfer of innovation is normally accompanied with the benefit transfer or payment of certain risk cost, it is necessary for the enterprises undertaking e-Business to weigh carefully if to transfer risks and which mode to be taken for risk transfer. Normally, when the technical risk and business risk is not greater than the financial risk, the financial transfer can be adopted. When the technical risk or business risk is greater, the objective transfer can be adopted.

(2) Risk distribution

Risk distribution for technological innovation of e-Services technological innovation means to reduce the overall risk by selecting the composition of proper technological innovation projects and carrying out the composed development of innovation. Theoretically speaking, when the mutual independence between different projects in the innovation project composition is stronger or of negative association, it will be more beneficial to reduce the overall risk of the project composition. However, due to the available conditions of Chinese enterprises undertaking eBusiness, such as fields with technical advantages and market share, it is difficult for them to be independent and non-associated in selecting the project composition. Besides, the excessive independence between projects will increase the innovation cost and enhance the innovation difficulty due to the non-effective sharing of technical resources, human resources and production resources. Therefore, it is necessary to maintain a certain association between projects if to distribute technological innovation risks by means of project composition.

(3) Risk control

Risk control for technological innovation of e-Services means to carry out precontrol over the innovation risks and reduce the possibility of risks and loss of the existing risks under the circumstance of having thorough identification and analysis on the risk factors of innovation. Risk factors for technological innovation of China's e-Services include controllable risk factor and uncontrollable risks factor. Some factors for decision-making risk, technical risk and production risk are in the category of controllable factors, which can be prevented and controlled by means of planning, organization and coordination. As for the uncontrollable factors of risks due to macro policy environment and market demand, such risk prevention modes as 
risk transfer and distribution. Chinese enterprises undertaking e-Business can also establish the risk alarming system for innovation to carry out the assessment and forecast of risks, deliver timely different-extent alarming as per nature and extent of risks and carry out the pre-control over the technological innovation risk of eServices.

\section{References}

1. WmChi and $\mathrm{Zq}$ Lin. Technical Composition of and Key Problems for Current eBusiness. Guangdong Education, 2006 (4), pp. 57-59

2. Mx Huang and XI Li. Study on Quality of e-Service. Information Journal, 2005(8), pp. $20-22$

3. Hx Xie. Demonstrative Study on Technological Innovation Risks of Search-engine Enterprises. Library information Service, 2007(2), pp. 18-22

4. Hg Qin and JCui. Type, Reason and Countermeasures of Enterprises' Technological Innovation Risk. Business Study, 2002(242), pp. 23-25

5. Xiaobin Lu. Study on Technological Innovation Models for Chinese Consulting Enterprises. Library information Service, 2007(2), pp. 10-14

6. Julie Gable. Innovations in Information Management Technologies. Information Management Journal. Lemexa: Jan/Feb 2004. Vol. 38, pp. 156-159 